\title{
Individual and joint toxic effects of cadmium sulfate and $\alpha$-naphthoflavone on the development of zebrafish embryo*
}

\author{
Jian YIN $^{\dagger 1}$, Jian-ming YANG ${ }^{1}$, Feng ZHANG ${ }^{2}$, Peng MIAO ${ }^{1,3}$, Ying LIN $^{1}$, Ming-li CHEN ${ }^{1}$ \\ $\left({ }^{1}\right.$ CAS Key Lab of Bio-Medical Diagnostics, Suzhou Institute of Biomedical Engineering and Technology, \\ Chinese Academic of Sciences, Suzhou 215163, China) \\ ( ${ }^{2}$ Suzhou Xiexin Photovoltaic Technology Co., Ltd., Suzhou 215163, China) \\ $\left({ }^{3}\right.$ University of Chinese Academy of Sciences, Beijing 100049, China) \\ †E-mail: yinj@sibet.ac.cn
}

Received Apr. 3, 2014; Revision accepted July 23, 2014; Crosschecked Aug. 15, 2014

\begin{abstract}
This paper aims to evaluate the individual and joint toxicities of cadmium sulfate $\left(\mathrm{CdSO}_{4}\right)$ and a-naphthoflavone (ANF) in zebrafish embryos. As a result, $\mathrm{CdSO}_{4}$ caused both lethal and sub-lethal effects, such as $24 \mathrm{~h}$ post-fertilization (hpf) death and $72 \mathrm{hpf}$ delayed hatching. However, ANF only caused sub-lethal effects, including $48 \mathrm{hpf}$ cardiac edema and $72 \mathrm{hpf}$ delayed hatching. Taking $24 \mathrm{hpf}$ death and $48 \mathrm{hpf}$ cardiac edema as endpoints, the toxicities of $\mathrm{CdSO}_{4}$ and ANF were significantly enhanced by each other. Consistently, both $\mathrm{CdSO}_{4}$ and ANF caused significant oxidative stress, including decreases in the reduced glutathione (GSH) level, inhibition of superoxide dismutase (SOD) activity, as well as increases in malondialdehyde (MDA) content in zebrafish embryos, but these mixtures produced much more significant alterations on the biomarkers. Co-treatment of $\mathrm{CdSO}_{4}$ and ANF significantly down-regulated the mRNA level of multidrug resistance-associated protein (mrp) 1 and cytochrome P450 (cyp) 1a, which constituted the protective mechanisms for zebrafish embryos to chemical toxins. In conclusion, co-treatment of $\mathrm{CdSO}_{4}$ and $\mathrm{ANF}$ exhibited a much more severe damage in zebrafish embryos than individual treatment. Meanwhile, production of oxidative stress and altered expression of mrp1 and cyp1a could be important components of such joint toxicity.
\end{abstract}

Key words: Joint toxicity, Cadmium sulfate, a-Naphthoflavone, Zebrafish embryo, Oxidative stress doi:10.1631/jzus.B1400091 Document code: A CLC number: Q89

\section{Introduction}

Aquatic organisms are usually faced with various types of chemical toxicants in the water, and thus have to suffer from the unpredictable interactions of these mixtures (Duan et al., 2008; Maria and Bebianno, 2011). Unfortunately, although there have been numerous investigations on the toxicity of a specific compound (Shi et al., 2008; Osterauer et al., 2011), information regarding the joint effects of pollutants remains insufficient.

\footnotetext{
* Project supported by the National Natural Science Foundation of China (No. 21307154)

(C) Zhejiang University and Springer-Verlag Berlin Heidelberg 2014
}

Cadmium is one of the most important heavy metal toxicants and its environmental concentration is increasing due to its extensive utilization in modern industries. Cadmium is reported to cause many deleterious effects including impaired neurogenesis, eye defects, and hatching failure in aquatic organisms (Chow et al., 2008; Matović et al., 2011). Various experiments have been done on zebrafish, Sparus aurata, and gilthead sea bream larvae, and the results revealed that the toxicity of cadmium was caused by the inhibition of cytochrome P450 (CYP) 1A expression as well as the production of oxidative stress (Sassi et al., 2013; Souid et al., 2013; Wang and Gallagher, 2013).

Polycyclic aromatic hydrocarbon (PAH), on the 
other hand, consists of a large number of compounds with different structures, and is increasingly released by oil leakages, vehicle emissions, and agriculture/ industry activities. In aquatic systems, PAHs like benzo $[\alpha]$ pyrene and retene pose significant threats, such as pericardial edema, craniofacial malformations, and altered development of visual systems in fishes (Fleming and di Giulio, 2011; Hawliczek et al., 2012; Huang et al., 2014). And such threats are reportedly related to the metabolism by CYP1A as well as enhanced levels of oxidative stress (Timme-Laragy et al., 2007).

Adenosine triphosphate-binding cassette (ABC) transporters, such as multidrug resistance-associated protein (Mrp) 1-5 genes, have also been considered to be involved in the detoxification of cadmium and PAH. High expression and function of these transporters have been found in fishes, such as zebrafish (Long et al., 2011a; 2011b) and rainbow trout (Kennedy et al., 2014). Their gene expression could be induced by various xenobiotics like cadmium and $\mathrm{PAH}$, pumping the parent compound and their metabolites out of the organisms in an energy-dependent process (Long et al., 2011c; Costa et al., 2012; Navarro et al., 2012). Thus, ABC transporters are usually considered to be the major biological defense mechanism for the protection of organisms against these environmental chemicals.

Due to their wide applications, cadmium and PAH usually coexist in the environment (Zhang et al., 2004; Keenan et al., 2010), and interactions of these chemicals in fishes might happen due to the similar induction of oxidative stress and the involvement of CYP1A and ABC transporters. However, such interactions have never been studied in previous experiments. In this paper, zebrafish embryos, which represented an attractive model for studying the toxic mechanisms of environmental chemicals (Berry et al., 2007; Weil et al., 2009), were used to examine the individual and joint effects of cadmium sulfate $\left(\mathrm{CdSO}_{4}\right)$ and a model PAH, $\alpha$-naphthoflavone (ANF) (Timme-Laragy et al., 2007). To assess the possible role of oxidative stress, $\mathrm{ABC}$ transporters and CYP1A in the joint toxicity, the alteration of reduced glutathione (GSH) level, superoxide dismutase (SOD) activity, malondialdehyde (MDA) content, and $\mathrm{mrp} 1$ and cypla expression caused by $\mathrm{CdSO}_{4}, \mathrm{ANF}$, and $\mathrm{CdSO}_{4}$-ANF mixtures were respectively evaluated.

\section{Materials and methods}

\subsection{Reagents}

Both $\mathrm{CdSO}_{4}$ and ANF were obtained from Sinopharm Chemical Reagent Co., Ltd. (Shanghai, China), and their purity was above $99 \%$. Kits for GSH level, SOD activity, and MDA content were obtained from Beyotime Institute of Biotechnology (Nantong, China). The other reagents were of reagent grade and purchased from local suppliers.

\subsection{Zebrafish}

Adult wide-type zebrafish were purchased from a local aquarium (Suzhou, China) and maintained as described before (Berry et al., 2007). Fish eggs were collected and washed three times with Holtfreter's buffer $\left(3.5 \mathrm{~g} / \mathrm{L} \mathrm{NaCl}, 0.05 \mathrm{~g} / \mathrm{L} \mathrm{KCl}, 0.1 \mathrm{~g} / \mathrm{L} \mathrm{CaCL}_{2}\right.$, and $0.025 \mathrm{~g} / \mathrm{L} \mathrm{NaHCO}$; $\mathrm{pH}$ 7.5). Using an Axio Observer A1 microscope (Carl Zeiss, Inc., Oberkochen, Germany), the status of the collected eggs was visually determined, and any dead eggs were discarded. At $4 \mathrm{~h}$ post-fertilization (hpf), the goodquality eggs were collected and placed in a $24-$ well plate such that each well contained 10 embryos, and were used for developmental toxicity assays (Tilton and Tanguay, 2008).

\subsection{Developmental toxicity test}

$\mathrm{CdSO}_{4}$ was dissolved in Holtfreter's buffer directly before use. ANF was dissolved in acetone first and then diluted in Holtfreter's buffer. In each treatment, the concentration of acetone was no more than $0.1 \%$, which caused no significant alteration in the development of embryos.

At $4 \mathrm{hpf}$, eggs in 24-well plates were washed with Holtfreter's buffer and exposed to $2 \mathrm{ml}$ Holtfreter's buffer containing the vehicle, $\mathrm{CdSO}_{4}, \mathrm{ANF}$, or $\mathrm{CdSO}_{4}$ ANF mixtures. Each group contained at least six replicates, and eggs treated by $0.1 \%$ acetone acted as vehicle controls. Moreover, transparent plastic film was used to cover the wells. Half of the exposure solutions of each well were removed and then were replaced daily with fresh exposure solutions. Meanwhile, the dead animals were removed. At 24, 48, and $72 \mathrm{hpf}$, the developmental status of the zebrafish embryos treated by vehicle control (Figs. 1a and 1c) and chemicals (Figs. 1b and 1d) was observed with the microscope and documented using a A2000IS 

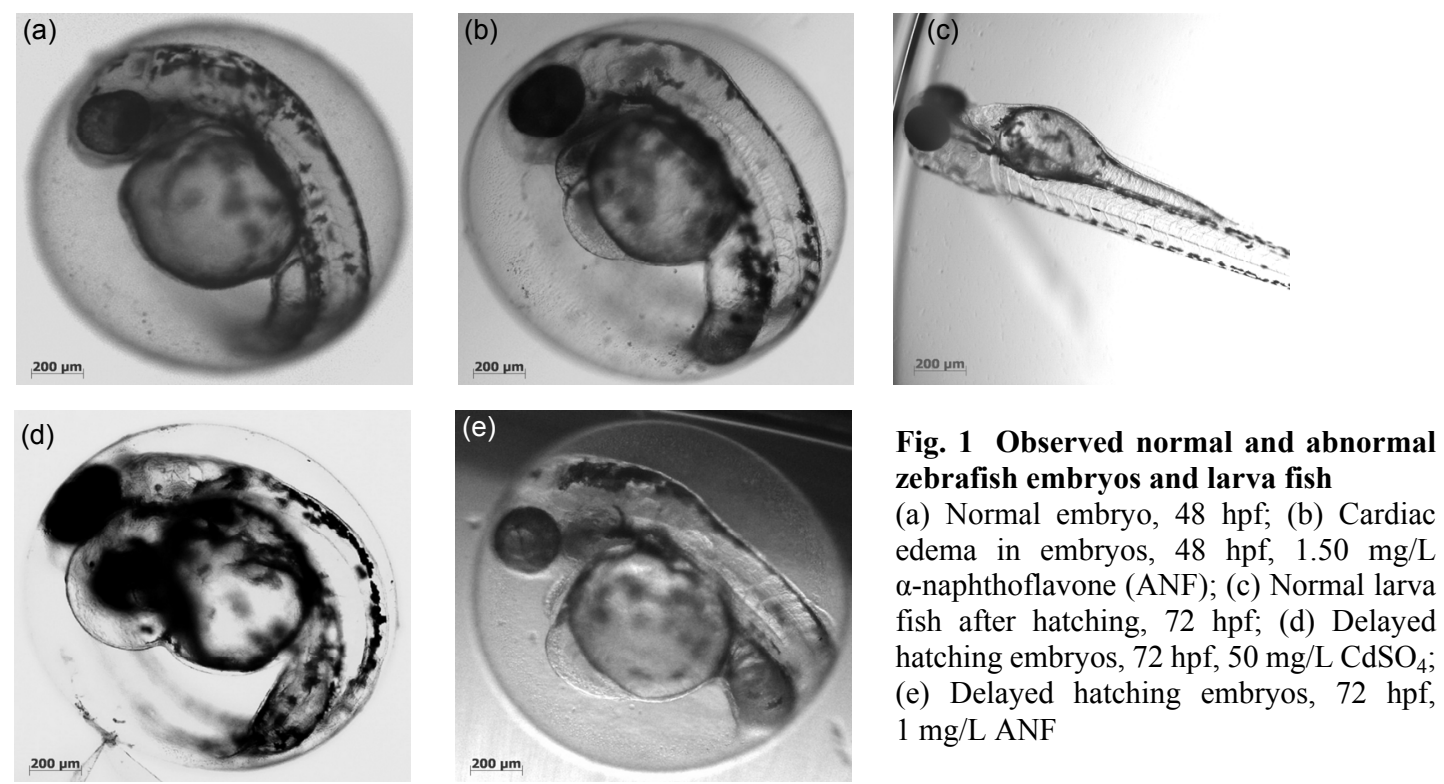

camera (Conan Co., Ltd., Beijing, China). The selected endpoints included $24 \mathrm{hpf}$ death, $48 \mathrm{hpf}$ cardiac edema (Fig. 1b), and 72 hpf delayed hatching (Figs. 1d and 1e).

To more specifically identify the effect of ANF on the toxicity of $\mathrm{CdSO}_{4}$, we also conducted an experiment in which embryos were first treated by $75 \mathrm{mg} / \mathrm{L} \mathrm{CdSO}_{4}$ alone, and then $12 \mathrm{~h}$ later, the embryos were washed with Holtfreter's buffer and exposed to the mixtures of $75 \mathrm{mg} / \mathrm{L} \mathrm{CdSO}_{4}$ and $1.5 \mathrm{mg} / \mathrm{L} \mathrm{ANF}$. Mortalities of zebrafish embryos after $20 \mathrm{~h}$ treatment (16-36 hpf) were subsequently recorded and compared with groups treated only by $\mathrm{CdSO}_{4}(4-36 \mathrm{hpf})$ or the simultaneous treatment of $\mathrm{CdSO}_{4}$ and ANF (4-24 hpf).

\subsection{GSH, MDA, and SOD detection}

At 24, 36, and $48 \mathrm{hpf}$, three sets of 60 embryos in both the vehicle control and chemical treatment groups were washed with Holtfreter's buffer and collected into $1.5 \mathrm{ml}$ centrifuge tubes. Each tube was filled with $300 \mu \mathrm{l}$ phosphate buffer solution (PBS; $\mathrm{pH}$ 7.4) and immersed in liquid nitrogen for $20 \mathrm{~s}$. After that, the embryos in PBS were mechanically homogenized (Wiegand et al., 1999). The supernatant was collected after the centrifugation of the embryo homogenate $\left(10000 \times g, 4{ }^{\circ} \mathrm{C}, 10 \mathrm{~min}\right)$ for a biomarkers assay.

GSH level, SOD activity, and MDA content were detected using commercially available kits. The protein content of supernatants was detected using the bicinchoninic acid method (Walker, 1994). The GSH level was determined via the formation of 5-thio2-nitrobenzoic acid (412 nm) (Hao et al., 2013). SOD activity was detected by the nitroblue tetrazolium/ riboflavin photometric quantitative methods $(420 \mathrm{~nm})$ (Janknegt et al., 2007). The content of MDA was detected using the thiobarbituric acid assay (535 nm) (Dong et al., 2013). All the biomarker detections were conducted with the Synergy HT multi-mode microplate reader (Bio-Tek Instruments, Inc., Vermont, USA). After this, all the biomarkers were normalized to the total protein content and expressed as a percentage of the groups treated by the vehicle.

\subsection{Reverse transcriptase-polymerase chain reac- tion (RT-PCR) analyses of cypla and mrpl}

At 24 and $48 \mathrm{hpf}$, zebrafish embryos treated by the vehicle, $75 \mathrm{mg} / \mathrm{L} \mathrm{CdSO}_{4}, 1.5 \mathrm{mg} / \mathrm{L} \mathrm{ANF}$, or the mixtures of $75 \mathrm{mg} / \mathrm{L} \mathrm{CdSO}_{4}$ and $1.5 \mathrm{mg} / \mathrm{L} \mathrm{ANF}$ were collected. The living ones were used to extract total RNA with a commercial kit (Axygen Scientific, Inc., USA). The RNA quality was checked by $260 / 280 \mathrm{~nm}$ absorption using a NanoDrop 2000 spectrophotometer (Thermo Fisher Scientific, Inc., USA). First-strand cDNA was prepared as previously described by Nakashima et al. (2012). After this, glyceraldehyde3-phosphate dehydrogenase (gapdh), mrp1, and cypla were amplified from the first-strand cDNA using the PCR. Among these, gapdh was set as the house keeping gene. Gene primer sequences of gapdh, mrp1, 
and cypla (Table 1) were designed using Primer Premier 5.0 software (Premier, Inc., Canada).

\subsection{Statistical analysis}

All of the experimental data were expressed as mean \pm standard deviation (SD) of three sets of independent experiments, which were subsequently analyzed using a Statistical Package for Social Sciences (SPSS) v.15.0 (Chicago, USA). One-way analysis of variance (ANOVA) for multiple groups and Tukey's HSD tests for two different treatments were performed to compare the data, respectively. In all cases, data differences were statistically significant when $P<0.05$.

\section{Results}

\subsection{Individual toxicities of $\mathrm{CdSO}_{4}$ and $\mathrm{ANF}$}

As shown in Figs. 1 and 2, zebrafish embryos treated by the vehicle control $(0.1 \%$ acetone $)$ exhibited no significant alteration. $\mathrm{CdSO}_{4}$ revealed both lethal and differential sub-lethal effects, like $24 \mathrm{hpf}$ death and 72 hpf delayed hatching (Fig. 1d). However, only sub-lethal effects, such as $48 \mathrm{hpf}$ cardiac edema (Fig. 1b) and $72 \mathrm{hpf}$ delayed hatching (Fig. 1e) were observed for ANF. Furthermore, concentrationdependent toxic effects of both toxic compounds were obtained and are shown in Fig. 2. For example, the mortality of the embryos at $24 \mathrm{hpf}$ was $(10.00 \pm 4.61) \%$ after a treatment of $100 \mathrm{mg} / \mathrm{L} \mathrm{CdSO}_{4}$, while, all embryos were dead at $24 \mathrm{hpf}$ when exposed to $300 \mathrm{mg} / \mathrm{L} \mathrm{CdSO}_{4}$. The treatment of $20 \mathrm{mg} / \mathrm{L} \mathrm{CdSO}_{4}$ caused a delayed hatching rate of $(17.50 \pm 5.00) \%$ at $72 \mathrm{hpf}$, while the delayed hatching rate increased to $100 \%$ when the embryos were treated by $75 \mathrm{mg} / \mathrm{L}$ $\mathrm{CdSO}_{4}$. For ANF, a similar trend was also found. For example, exposure to $1 \mathrm{mg} / \mathrm{L}$ ANF resulted in a cardiac edema rate of $(26.25 \pm 10.15) \%$ at $48 \mathrm{hpf}$, while nearly all embryos had cardiac edema at $48 \mathrm{hpf}$ after the treatment of $3 \mathrm{mg} / \mathrm{L}$ ANF.

\subsection{Joint toxicity of $\mathrm{CdSO}_{4}$ and ANF}

Since 24 hpf death only occurred in embryos treated by $\mathrm{CdSO}_{4}$ and $48 \mathrm{hpf}$ cardiac edema in embryos was only observed after the treatment of ANF, they were selected as endpoints for the investigation of the joint toxicity of $\mathrm{CdSO}_{4}$ and ANF. As a result, toxicities of $\mathrm{CdSO}_{4}$ and ANF could be significantly enhanced by each other (Fig. 3). For example, the treatment of $75 \mathrm{mg} / \mathrm{L} \mathrm{CdSO}_{4}$ or $1.5 \mathrm{mg} / \mathrm{L}$ ANF alone did not cause any death of zebrafish embryos, but co-treatment of $1.5 \mathrm{mg} / \mathrm{L} \mathrm{ANF}$ and $75 \mathrm{mg} / \mathrm{L} \mathrm{CdSO}_{4}$ resulted in a 24 hpf mortality of $(31.11 \pm 6.12) \%$. Furthermore, all embryos were dead at $24 \mathrm{hpf}$ after exposure to the co-treatment of $1.5 \mathrm{mg} / \mathrm{L} \mathrm{ANF}$ and $150 \mathrm{mg} / \mathrm{L} \mathrm{CdSO}_{4}$, while they were all alive when treated by $\mathrm{CdSO}_{4}$ or ANF alone $(P>0.05)$. Similarly, the treatments of $1.5 \mathrm{mg} / \mathrm{L} \mathrm{ANF}$ and $75 \mathrm{mg} / \mathrm{L} \mathrm{CdSO}_{4}$ resulted in a $48 \mathrm{hpf}$ cardiac edema rate of $(58.33 \pm$ $12.93) \%$ and 0 , respectively, but the cardiac edema rate was $(85.00 \pm 4.25) \%$ when embryos were treated by a combination of $75 \mathrm{mg} / \mathrm{L} \mathrm{CdSO}_{4}$ and $1.5 \mathrm{mg} / \mathrm{L}$ ANF $(P<0.001)$.

\subsection{Altered oxidative stress state of zebrafish embryos by the individual treatments of $\mathrm{CdSO}_{4}$ and ANF}

Generally, $\mathrm{CdSO}_{4}$ and ANF caused a concentrationand time-dependent alteration of the GSH level, SOD activity, and MDA content (Fig. 4). For example, SOD activity at $24 \mathrm{hpf}$ was unaffected by $100 \mathrm{mg} / \mathrm{L}$ $\mathrm{CdSO}_{4}$, but it was reduced by $9 \%$ when treated by $200 \mathrm{mg} / \mathrm{L} \mathrm{CdSO}_{4}$. Meanwhile, the reduction of SOD activity at $48 \mathrm{hpf}$ was about $25 \%$ when embryos were treated by $200 \mathrm{mg} / \mathrm{L} \mathrm{CdSO}_{4}$ (Figs. 4a and 4b). Besides, the effects of ANF on GSH level, SOD activity, and MDA content of embryos at $48 \mathrm{hpf}$ were not

Table 1 Specific primer sequences used in this experiment

\begin{tabular}{clcc}
\hline Gene & \multicolumn{1}{c}{ Primer sequence $\left(5^{\prime} \rightarrow 3^{\prime}\right)$} & Product size $(\mathrm{bp})$ & Reference \\
\hline gapdh & Sense: GCAACACAGAAGACCGTTGA & 440 & NM_001115114.1 \\
& Anti-sense: GCCATCAGGTCACATACACG & & \\
mrpl & Sense: TTGGATGGAGCTGGGTTTCC & 437 & XM_001341859.4 \\
& Anti-sense: CTGAACTGCCACCTCGCTTA & & \\
\multirow{2}{*}{ cypla } & Sense: TGATGGAAAGAGTCTGGCGT & 457 & NM_131879.1 \\
& Anti-sense: CTCCATCACCAGCCTCTTCA & & \\
\hline
\end{tabular}



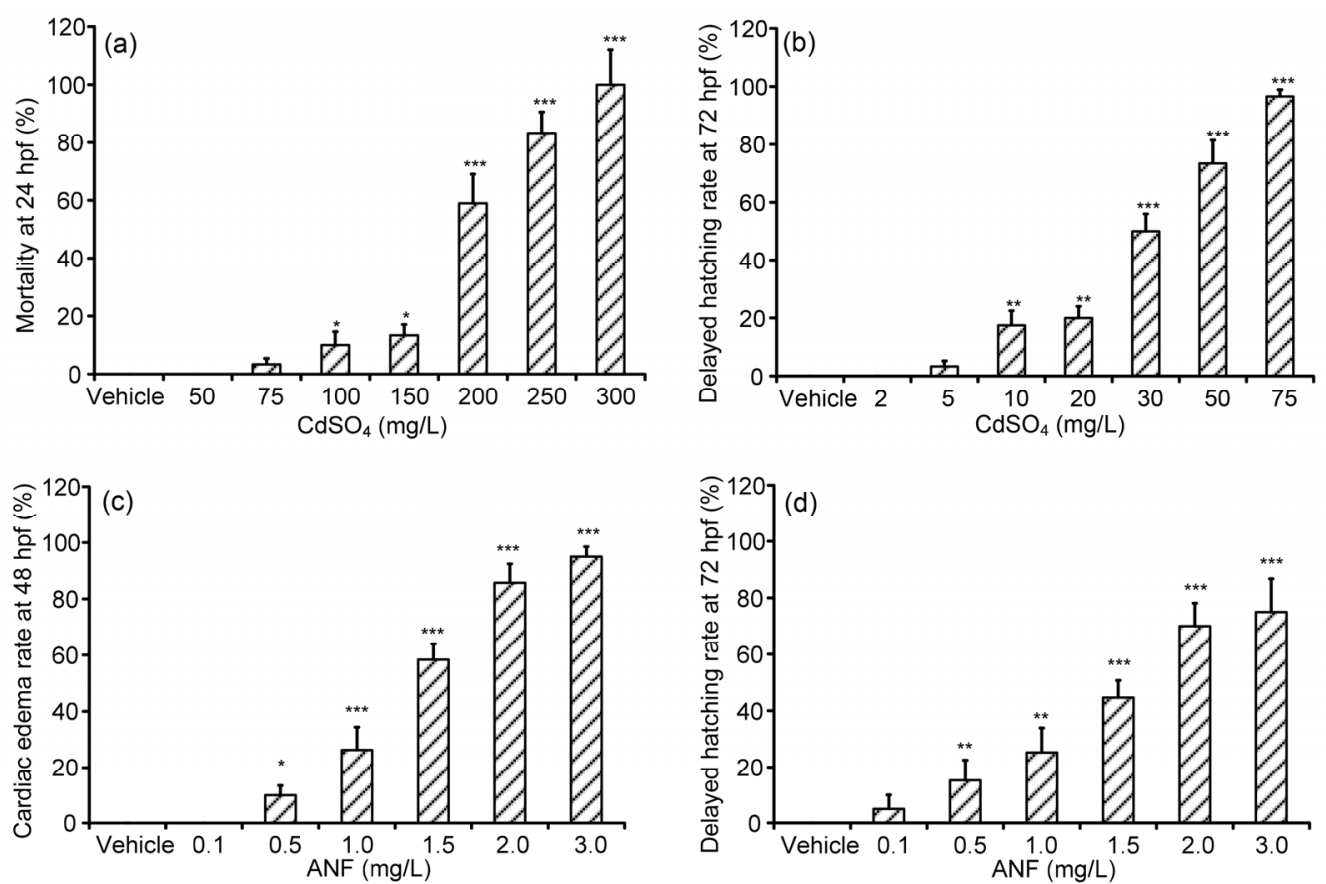

Fig. 2 Concentration-response relations for cadmium sulfate $\left(\mathrm{CdSO}_{4}\right)$ and $\alpha$-naphthoflavone (ANF) alone (a) Mortality at $24 \mathrm{hpf}, \mathrm{CdSO}_{4}$; (b) Delayed hatching rate at $72 \mathrm{hpf}, \mathrm{CdSO}_{4}$; (c) Cardiac edema rate at $48 \mathrm{hpf}$, ANF; (d) Delayed hatching rate at $72 \mathrm{hpf}$, ANF. Cardiac edema rate is the percentage of embryos having cardiac edema; delayed hatching rate is the percentage of embryos which exhibited delayed hatching. ${ }^{*} P<0.05,{ }^{* *} P<0.01,{ }^{* * *} P<0.001$, compared with the vehicle control. Values are expressed as mean $\pm \mathrm{SD}$ of three sets of independent experiments
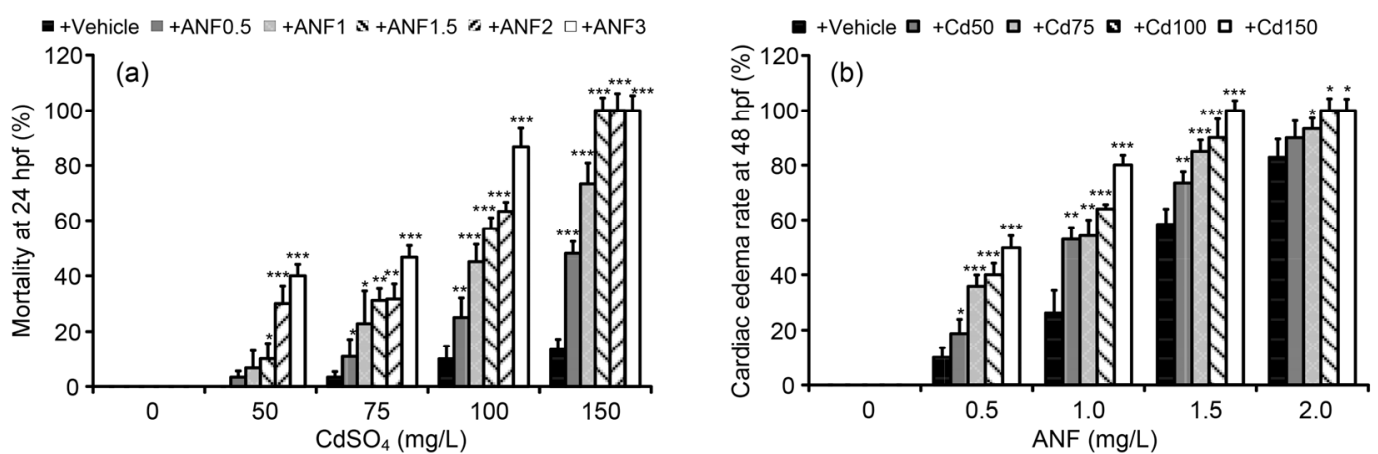

Fig. 3 Concentration-response relations for the combination of cadmium sulfate (CdSO ${ }_{4}$ ) and $\alpha$-naphthoflavone (ANF) (a) Mortality at $24 \mathrm{hpf}$; (b) Cardiac edema rate at $48 \mathrm{hpf}$. Cardiac edema rate is the percentage of embryos having cardiac edema. ANF0.5, ANF1, ANF1.5, ANF2, and ANF3: 0.5, 1.0, 1.5, 2.0, and $3.0 \mathrm{mg} / \mathrm{L} \mathrm{ANF;} \mathrm{Cd50,} \mathrm{Cd75,} \mathrm{Cd100,} \mathrm{and} \mathrm{Cd150:}$ $50,75,100$, and $150 \mathrm{mg} / \mathrm{L} \mathrm{CdSO}_{4} \cdot{ }^{*} P<0.05,{ }^{* *} P<0.01,{ }^{* * *} P<0.001$, compared with the groups treated by $\mathrm{CdSO}_{4}($ a) or ANF (b) only. Values are expressed as mean \pm SD of three sets of independent experiments

significant unless a concentration of $2 \mathrm{mg} / \mathrm{L}$ was used (Figs. 4c and 4d).

\subsection{Altered oxidative stress state of zebrafish embryos by the co-treatment of $\mathrm{CdSO}_{4}$ and $\mathrm{ANF}$}

Consistent with the joint toxicity of $\mathrm{CdSO}_{4}$ and ANF, the mixtures produced great oxidative stress, including decreases in the GSH level, inhibition of SOD activity, and increase in MDA content, whereas no significant effects on the biomarkers were induced by the individuals at the corresponding doses (Fig. 5). For example, the SOD activity in embryos at $48 \mathrm{hpf}$ was nearly completely inhibited by the co-treatment of $75 \mathrm{mg} / \mathrm{L} \mathrm{CdSO}_{4}$ and $1.5 \mathrm{mg} / \mathrm{L} \mathrm{ANF}$, but it was unaffected by the individual treatment of either compound $(P>0.05)$. Besides, the alteration in this biomarker was more pronounced with an increasing exposure period. 

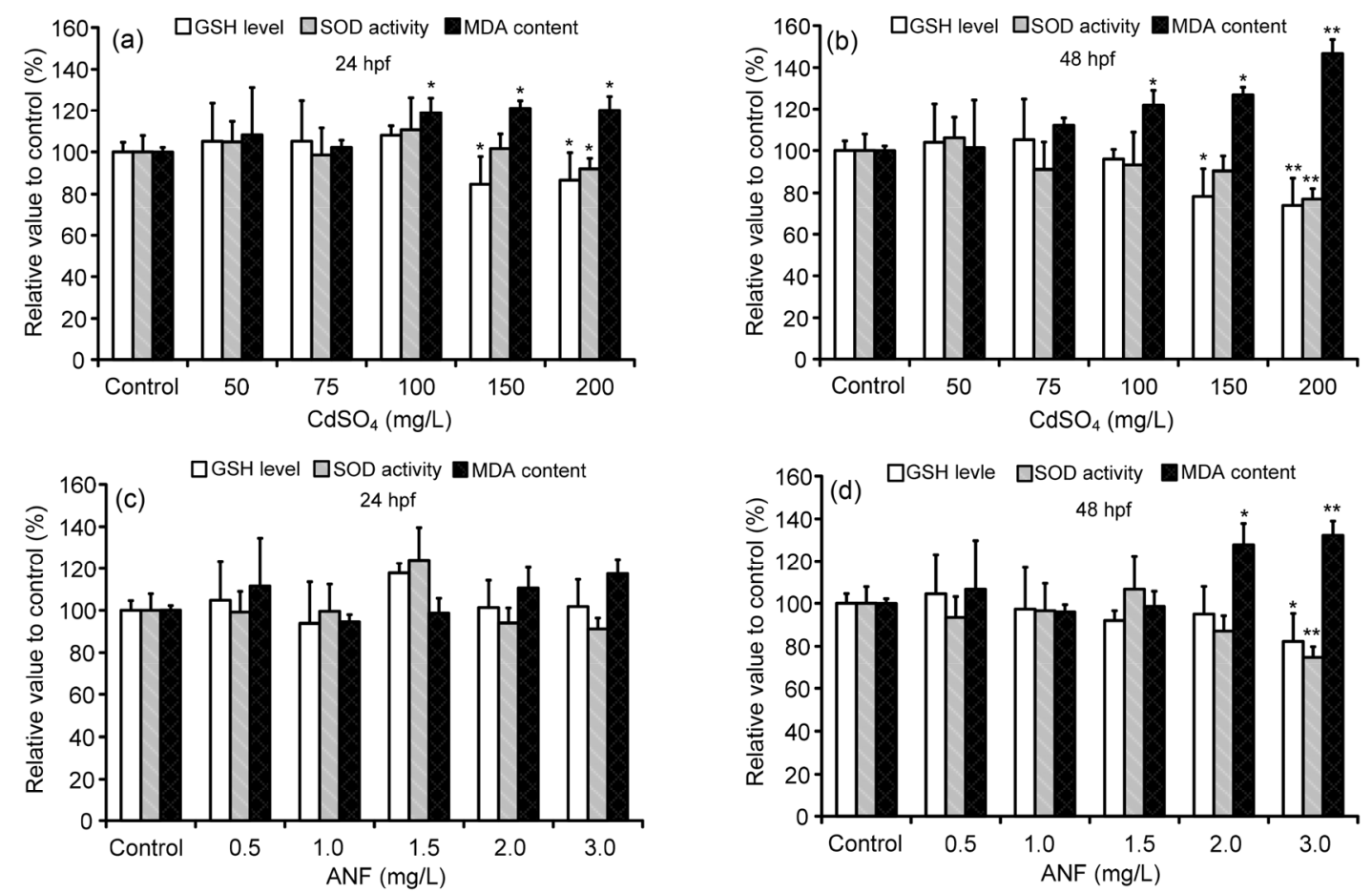

Fig. 4 Changes of oxidative stress state in zebrafish embryos at $24 \mathrm{hpf}(\mathrm{a}, \mathrm{c})$ and $\mathbf{4 8} \mathrm{hpf}(\mathrm{b}, \mathrm{d})$ upon exposure to cadmium sulfate $\left(\mathrm{CdSO}_{* * *}\right)(\mathrm{a}, \mathrm{b})$ and $\alpha$-naphthoflavone (ANF) (c, d)

${ }^{*} P<0.05,{ }^{* *} P<0.01,{ }^{* * *} P<0.001$, compared with the vehicle control. Values are expressed as mean $\pm \mathrm{SD}$ of three sets of independent experiments
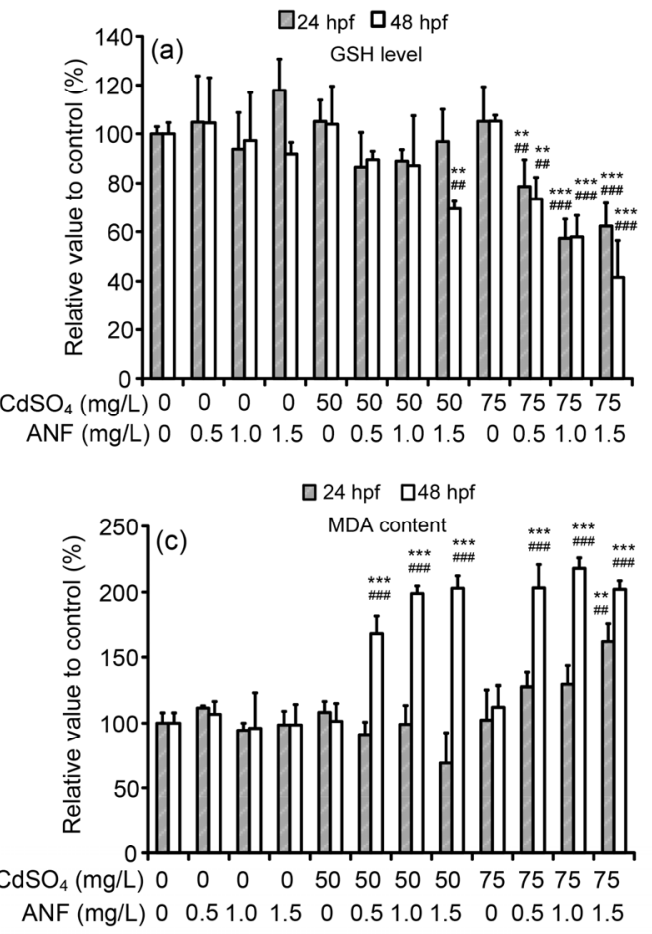

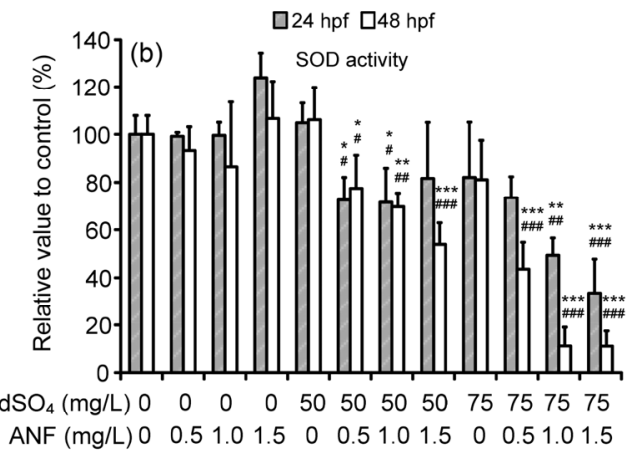

Fig. 5 Changes of oxidative stress state in zebrafish embryos at 24 and $48 \mathrm{hpf}$ upon exposure to the combination of cadmium sulfate ( $\left.\mathrm{CdSO}_{4}\right)$ and $\alpha$-naphthoflavone (ANF) (a) Glutathione (GSH) level; (b) Superoxide dismutase (SOD) activity; (c) Malondialdehyde (MDA) content. ${ }^{*} P<0.05$, ${ }^{* *} P<0.01,{ }^{* * *} P<0.001$, compared with the groups treated by $\mathrm{CdSO}_{4}$ only; ${ }^{\#} P<0.05,{ }^{\#} P<0.01,{ }^{\# \#} P<0.001$, compared with the groups treated by ANF only. Values are expressed as mean $\pm \mathrm{SD}$ of three sets of independent experiments 


\subsection{Toxicity of $\mathrm{CdSO}_{4}$-ANF mixtures after a 12-h pre-treatment of $\mathrm{CdSO}_{4}$}

To more specially illustrate the mechanism of the interactions between $\mathrm{CdSO}_{4}$ and ANF, we added $1.5 \mathrm{mg} / \mathrm{L}$ ANF $12 \mathrm{~h}$ after the pre-treatment of $75 \mathrm{mg} / \mathrm{L}$ $\mathrm{CdSO}_{4}$ alone. As a result, such a treatment caused a much lower mortality and slighter alteration of an oxidative stress state than the simultaneous addition of $75 \mathrm{mg} / \mathrm{L} \mathrm{CdSO}_{4}$ and $1.5 \mathrm{mg} / \mathrm{L}$ ANF (Table 2). For example, after $12 \mathrm{~h}$ pre-treatment of $\mathrm{CdSO}_{4}$, the mixtures of $\mathrm{CdSO}_{4}$ and ANF caused a reduction of SOD activity by $22 \%$, while the simultaneous addition of $\mathrm{CdSO}_{4}$ and ANF decreased the activity of SOD by about $67 \%(P<0.05)$. The addition of $1.5 \mathrm{mg} / \mathrm{L}$ ANF only slightly enhanced the toxicity compared with the group treated by $75 \mathrm{mg} / \mathrm{L} \mathrm{CdSO}_{4}$ alone. For instance, the $36 \mathrm{hpf}$ mortality of embryos after the co-treatment of $\mathrm{CdSO}_{4}$ and ANF was $(15.23 \pm 2.04) \%$, which was only slightly higher than that of embryos treated by $\mathrm{CdSO}_{4}$ alone ((3.96 \pm 4.19$\left.) \%\right)$.

\subsection{Alteration of mrp1 and cyp1a gene expression}

After the treatments of $\mathrm{CdSO}_{4}, \mathrm{ANF}$, and $\mathrm{CdSO}_{4}$-ANF mixtures, mRNA expression levels of mrpl and cypla in zebrafish embryos at 24 and $48 \mathrm{hpf}$ were respectively detected. And the results indicated that the individual treatments of $75 \mathrm{mg} / \mathrm{L} \mathrm{CdSO}_{4}$ and $1.5 \mathrm{mg} / \mathrm{L} \mathrm{ANF}$ both significantly induced the gene expression of $m r p 1$, but the co-treatment of $75 \mathrm{mg} / \mathrm{L}$ $\mathrm{CdSO}_{4}$ and $1.5 \mathrm{mg} / \mathrm{L}$ ANF caused an obvious reduction of $m r p 1$ gene expression as compared with the vehicle controls. While for cypla, its gene expression was enhanced by ANF but inhibited by $\mathrm{CdSO}_{4}$, and the co-treatment of $\mathrm{CdSO}_{4}$ and $\mathrm{ANF}$ reduced the gene expression of cypla to near the level of the vehicle control. For both mrpl and cypla, the alteration of mRNA levels by chemicals seemed to be enhanced with incubation time.

\section{Discussion}

Aquatic organisms that inhabit environments are often contaminated with high levels of heavy metals and PAHs together (Terry and Stone, 2002; Udomchoke et al., 2010). However, studies on the joint effects of these pollutants are still rare. In this respect, $\mathrm{CdSO}_{4}$ and ANF were selected as the representatives of metals and $\mathrm{PAH}$, and their joint toxicity and corresponding mechanisms were subsequently studied.

Both $\mathrm{CdSO}_{4}$ and ANF exhibited significant developmental toxicity in zebrafish embryos (Figs. 1 and 2). Meanwhile, the toxicities of $\mathrm{CdSO}_{4}$ and ANF could be significantly enhanced by each other as observed based on $24 \mathrm{hpf}$ death and 48 hpf cardiac edema (Fig. 3). In the previous reports, glutathione $S$-transferase conjugation of GSH was considered to be important in the detoxification of cadmium in zebrafish embryos (Notch et al., 2011), while the treatment of ANF has been reported to significantly inhibit the activity of glutathione $S$-transferase and the subsequent antioxidant response in zebrafish embryos (Gauthier et al., 2014), indicating an interactive role of ANF with $\mathrm{CdSO}_{4}$. The modulation of glutathione $S$-transferase by cadmium (Matović et al., 2011; Yang et al., 2012) might also result in the enhancement of ANF toxicity, which was related to the production of oxidative stress (Fleming and di Giulio, 2011). In this paper, both $\mathrm{CdSO}_{4}$ and ANF caused decreases in the GSH level, inhibition of SOD activity, and increases in MDA content in zebrafish embryos (Fig. 4), but the mixtures produced a much greater oxidative stress (Fig. 5). Thus, oxidative stress should be considered important in the interaction of $\mathrm{CdSO}_{4}$ and ANF.

Interestingly, the same concentration of $\mathrm{CdSO}_{4}{ }^{-}$ ANF mixtures produced a reduced toxicity when the embryos were pretreated by $\mathrm{CdSO}_{4}$ for $12 \mathrm{~h}$ (Table 2), which should be due to the induction of the detoxification system by the pretreatment of $\mathrm{CdSO}_{4}$ (Fig. 6).

Table 2 Mortality and oxidative stress state of zebrafish embryos after the treatments of $\mathrm{CdSO}_{4}$-ANF mixtures and $\mathrm{CdSO}_{4}$

\begin{tabular}{lcccc}
\hline \multicolumn{1}{c}{ Treatment } & Morality (\%) & GSH level (\%) & SOD activity (\%) & MDA content (\%) \\
\hline $\begin{array}{l}\text { Simultaneous addition of } \mathrm{CdSO}_{4} \text { and } \\
\quad \text { ANF (4-24 hpf) }\end{array}$ & $31.11 \pm 6.12$ & $62.32 \pm 9.48$ & $33.55 \pm 14.26$ & $161.75 \pm 44.57$ \\
$\begin{array}{l}\text { Addition of ANF 12 h after the treatment } \\
\quad \text { of } \mathrm{CdSO}_{4} \text { alone (16-36 hpf) }\end{array}$ & $15.23 \pm 2.04^{\mathrm{a}}$ & $75.51 \pm 8.51^{\mathrm{a}, \mathrm{b}}$ & $78.03 \pm 5.34^{\mathrm{a}, \mathrm{b}}$ & $122.57 \pm 25.45$ \\
$\mathrm{CdSO}_{4}$ only (4-36 hpf) & $3.96 \pm 4.19$ & $101.12 \pm 12.14$ & $94.84 \pm 10.07$ & $107.14 \pm 20.53$ \\
\hline
\end{tabular}

Biomarkers are measured after $20 \mathrm{~h}$ treatment. Data, which are relative values to the control, are expressed as mean $\pm \mathrm{SD}$ of three independent experiments. ${ }^{1}$ Results were obtained directly from Figs. 3 and 5 . ${ }^{a} P<0.05$, compared with the groups treated by the simultaneous addition of $\mathrm{CdSO}_{4}$ and ANF; ${ }^{\mathrm{b}} \mathrm{P}<0.05$, compared with the groups treated by $\mathrm{CdSO}_{4}$ only 


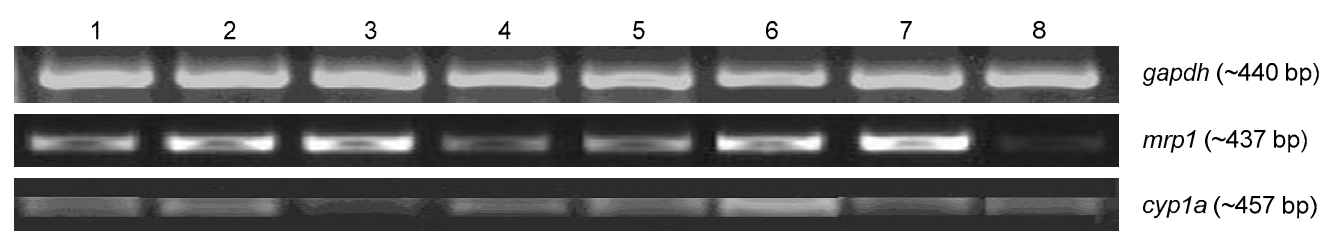

Fig. 6 RT-PCR analysis of the gene expression of gapdh, cyp1a, and mrp1

Results by PCR were from zebrafish embryos at $24 \mathrm{hpf}$ (Lanes 1-4) and $48 \mathrm{hpf}$ (Lanes 5-8). Lanes 1\&5: untreated embryos; Lanes 2\&6: embryos treated by $75 \mathrm{mg} / \mathrm{L} \mathrm{CdSO}_{4}$; Lanes 3\&7: embryos treated by $1.5 \mathrm{mg} / \mathrm{L} \mathrm{ANF}$; Lanes $4 \& 8$ : embryos treated by mixtures of $75 \mathrm{mg} / \mathrm{L} \mathrm{CdSO}_{4}$ and $1.5 \mathrm{mg} / \mathrm{L} \mathrm{ANF}$

RT-PCR results revealed that at sub-lethal concentrations, both $\mathrm{CdSO}_{4}$ and ANF could significantly induce the expression of $m r p 1$, correlating well with the previous reports and indicating that Mrp1 was involved in the detoxification of $\mathrm{CdSO}_{4}$ and $\mathrm{ANF}$ (Long et al., 2011c; Costa et al., 2012; Navarro et al., 2012). Based on the previous experiments, PAH and heavy metals can act as both the substrates and the competitive inhibitors of Mrps, and thus increase the tissue accumulation of each other when they were used together, which should be the reason for the enhanced toxicity of $\mathrm{CdSO}_{4}$-ANF mixtures. In addition, the reduced gene expression of mrpl by the co-treatment of $\mathrm{CdSO}_{4}$ and ANF could be explained by the fact that such $\mathrm{CdSO}_{4}$-ANF mixtures exceeded the capability of $\mathrm{ABC}$ transporters and caused significant death of zebrafish embryos (Fig. 4), thus decreasing the mRNA level of $m r p 1$ and further enhancing the toxicity of $\mathrm{CdSO}_{4}$-ANF mixtures. However, research on the role of multixenobiotic resistance (MXR) in the interaction of environmental chemicals is still rare, and further investigations are needed.

Furthermore, gene expression of cypla in zebrafish embryos at $24 \mathrm{hpf}$ was found to be significantly enhanced by ANF, but the addition of $\mathrm{CdSO}_{4}$ severely down-regulated the mRNA expression level of cypla. Furthermore, the co-treatment of $\mathrm{CdSO}_{4}$ and ANF decreased the gene expression to a level near to the control group. In previous experiments, the induction of cypla by various PAH like benzo[ $\alpha]$ pyrene and phenanthrene has been revealed to be a protective mechanism of the cardiovascular dysfunction in the development of zebrafish embryos (Billiard et al., 2008; Wills et al., 2009). Thus, the decreased gene expression of cyp 1 a by $\mathrm{CdSO}_{4}$ could significantly enhance the toxicity of ANF, especially when $48 \mathrm{hpf}$ cardiac edema was selected as the representing endpoint for ANF.

It needs to be mentioned that, cadmium and $\mathrm{PAH}$ levels in the rivers are $0.01-0.19 \mathrm{mg} / \mathrm{L}$ (Singh et al., 2008) and 0.2-2.0 $\mu \mathrm{g} / \mathrm{L}$ (Zhang et al., 2004), respectively, which are much lower than the concentrations used in this experiment. Such high concentrations could be first explained by the bioaccumulation of pollutants in the fish, making the tissue concentration many times higher than that in the surrounding waters (Vergauwen et al., 2013). Secondly, high concentrations of toxicants were usually used in laboratories to determine the possible toxic mechanism since they could exhibit significant effects in the short-term (Shi et al., 2008; Yu et al., 2012). In previous experiments, Konishi et al. (2006) found that the $72 \mathrm{hpf} \mathrm{LC}_{50}$ (lethal concentration $50 \%$ ) for $\mathrm{CdCl}_{2}$ was $1000 \mu \mathrm{mol} / \mathrm{L}$ $\left(\approx 208 \mathrm{mg} / \mathrm{L} \mathrm{CdSO}_{4}\right)$, which was similar to the concentration used in our experiments. ANF caused no death of embryos even to its solubility limit of $3 \mathrm{mg} / \mathrm{L}$ (data not shown) in this experiment, which should be due to its low oxidative damage (Fig. 4) and induced gene expression of mrpl and cypla (Fig. 6). This result corresponded well with the previous reports where $10 \mu \mathrm{mol} / \mathrm{L}$ ANF $(2.72 \mathrm{mg} / \mathrm{L})$ caused no death in differential fishes and was only used as CYP inhibitors (Meinelt et al., 2001; Koenig et al., 2012).

\section{Conclusions}

In conclusion, an enhancement of developmental toxicity by each other was observed when $\mathrm{CdSO}_{4}$ and ANF were used together. Production of oxidative stress and altered expression of mrpl and cypla could be the important components of such joint toxicity. In the future, this result should be confirmed with more typical $\mathrm{PAH}$, and the involvement of MXR in the interactions of $\mathrm{CdSO}_{4}$ and ANF should be investigated in detail.

\section{Compliance with ethics guidelines}

Jian YIN, Jian-ming YANG, Feng ZHANG, Peng MIAO, Ying LIN, and Ming-li CHEN declare that they have no conflict of interest.

All institutional and national guidelines for the care and use of laboratory animals were followed. 


\section{References}

Berry, J.P., Gantar, M., Gibbs, P.D., et al., 2007. The zebrafish (Danio rerio) embryo as a model system for identification and characterization of developmental toxins from marine and freshwater microalgae. Comp. Biochem. Physiol. C: Toxicol. Pharmacol., 145(1):61-72. [doi:10.1016/j.cbpc. 2006.07.011]

Billiard, S.M., Meyer, J.N., Wassenberg, D.M., et al., 2008. Nonadditive effects of PAHs on early vertebrate development: mechanisms and implications for risk assessment. Toxicol. Sci., 105(1):5-23. [doi:10.1093/toxsci/ $\mathrm{kfm} 303]$

Chow, E.S., Hui, M.N., Lin, C.C., et al., 2008. Cadmium inhibits neurogenesis in zebrafish embryonic brain development. Aquat. Toxicol., 87(3):157-169. [doi:10. 1016/j.aquatox.2008.01.019]

Costa, J., Reis-Henriques, M.A., Castro, L.F., et al., 2012. ABC transporters, CYP1A and GST $\alpha$ gene transcription patterns in developing stages of the Nile tilapia (Oreochromis niloticus). Gene, 506(2):317-324. [doi:10. 1016/j.gene.2012.06.092]

Dong, M., Zhu, L., Zhu, S., et al., 2013. Toxic effects of 1-decyl-3-methylimidazolium bromide ionic liquid on the antioxidant enzyme system and DNA in zebrafish (Danio rerio) livers. Chemosphere, 91(8):1107-1112. [doi:10. 1016/j.chemosphere.2013.01.013]

Duan, Z., Zhu, L., Kun, Y., et al., 2008. Individual and joint toxic effects of pentachlorophenol and bisphenol A on the development of zebrafish (Danio rerio) embryo. Ecotoxicol. Environ. Saf., 71(3):774-780. [doi:10.1016/j.ecoenv. 2008.01.021]

Fleming, C.R., di Giulio, R.T., 2011. The role of CYP1A inhibition in the embryotoxic interactions between hypoxia and polycyclic aromatic hydrocarbons (PAHs) and PAH mixtures in zebrafish (Danio rerio). Ecotoxicology, 20(6):1300-1314. [doi:10.1007/s10646-011-0686-1]

Gauthier, P.T., Norwood, W.P., Prepas, E.E., et al., 2014. Metal-PAH mixtures in the aquatic environment: a review of co-toxic mechanisms leading to more-than-additive outcomes. Aquat. Toxicol., 154:253-269. [doi:10.1016/j. aquatox.2014.05.026]

Hao, L., Chen, L., Hao, J., et al., 2013. Bioaccumulation and sub-acute toxicity of zinc oxide nanoparticles in juvenile carp (Cyprinus carpio): a comparative study with its bulk counterparts. Ecotoxicol. Environ. Saf., 91:52-60. [doi:10. 1016/j.ecoenv.2013.01.007]

Hawliczek, A., Nota, B., Cenijn, P., et al., 2012. Developmental toxicity and endocrine disrupting potency of 4-azapyrene, benzo[b]fluorene and retene in the zebrafish Danio rerio. Reprod. Toxicol., 33(2):213-223. [doi:10. 1016/j.reprotox.2011.11.001]

Huang, L., Zuo, Z., Zhang, Y., et al., 2014. Use of toxicogenomics to predict the potential toxic effect of benzo(a)pyrene on zebrafish embryos: ocular developmental toxicity. Chemosphere, 108:55-61. [doi:10.1016/j.chemosphere. 2014.02.078]

Janknegt, P.J., Rijstenbil, J.W., van de Poll, W.H., et al., 2007. A comparison of quantitative and qualitative superoxide dismutase assays for application to low temperature microalgae. J. Photochem. Photobiol. B, 87(3):218-226. [doi:10.1016/j.jphotobiol.2007.04.002]

Keenan, H.E., Bangkedphol, S., Sakultantimetha, A., et al.,
2010. The ecological complexity of the Thai-Laos mekong river: II. Metals and polyaromatic hydrocarbons (PAHs) monitoring, modelling and environmental fate. $J$. Environ. Sci. Health A: Tox. Hazard. Subst. Environ. Eng., 45(13):1674-1680. [doi:10.1080/10934529.2010.513208]

Kennedy, C.J., Tierney, K.B., Mittelstadt, M., 2014. Inhibition of $p$-glycoprotein in the blood-brain barrier alters avermectin neurotoxicity and swimming performance in rainbow trout. Aquat. Toxicol., 146:176-185. [doi:10. 1016/j.aquatox.2013.10.035]

Koenig, S., Fernandez, P., Sole, M., 2012. Differences in cytochrome p450 enzyme activities between fish and crustacea: relationship with the bioaccumulation patterns of polychlorobiphenyls (PCBs). Aquat. Toxicol., 108: 11-17. [doi:10.1016/j.aquatox.2011.10.016]

Konishi, T., Matsumoto, S., Tsuruwaka, Y., et al., 2006. Enhancing the tolerance of zebrafish (Danio rerio) to heavy metal toxicity by the expression of plant phytochelatin synthase. J. Biotechnol., 122(3):316-325. [doi:10. 1016/j.jbiotec.2005.12.013]

Long, Y., Li, Q., Cui, Z., 2011a. Molecular analysis and heavy metal detoxification of ABCC1/MRP1 in zebrafish. Mol. Biol. Rep., 38(3):1703-1711. [doi:10.1007/s11033-0100283-z]

Long, Y., Li, Q., Li, J., et al., 2011b. Molecular analysis, developmental function and heavy metal-induced expression of ABCC5 in zebrafish. Comp. Biochem. Physiol. B: Biochem. Mol. Biol., 158(1):46-55. [doi:10.1016/j.cbpb. 2010.09.005]

Long, Y., Li, Q., Wang, Y., et al., 2011c. MRP proteins as potential mediators of heavy metal resistance in zebrafish cells. Comp. Biochem. Physiol. C: Toxicol. Pharmacol., 153(3):310-317. [doi:10.1016/j.cbpc.2010.12.001]

Maria, V.L., Bebianno, M.J., 2011. Antioxidant and lipid peroxidation responses in Mytilus galloprovincialis exposed to mixtures of benzo(a)pyrene and copper. Comp. Biochem. Physiol. C: Toxicol. Pharmacol., 154(1):56-63. [doi:10.1016/j.cbpc.2011.02.004]

Matović, V., Buha, A., Bulat, Z., et al., 2011. Cadmium toxicity revisited: focus on oxidative stress induction and interactions with zinc and magnesium. Arch. Ind. Hyg. Toxicol., 62(1):65-76. [doi:10.2478/10004-1254-62-20112075]

Meinelt, T., Playle, R.C., Pietrock, M., et al., 2001. Interaction of cadmium toxicity in embryos and larvae of zebrafish (Danio rerio) with calcium and humic substances. Aquat. Toxicol., 54(3-4):205-215. [doi:10.1016/S0166-445X(01) 00145-X]

Nakashima, T., Jinnin, M., Yamane, K., et al., 2012. Impaired IL-17 signaling pathway contributes to the increased collagen expression in scleroderma fibroblasts. J. Immunol., 188(8):3573-3583. [doi:10.4049/jimmunol.1100591]

Navarro, A., Weissbach, S., Faria, M., et al., 2012. ABCB and $\mathrm{ABCC}$ transporter homologs are expressed and active in larvae and adults of zebra mussel and induced by chemical stress. Aquat. Toxicol., 122-123:144-152. [doi:10.1016/ j.aquatox.2012.06.008]

Notch, E.G., Miniutti, D.M., Berry, J.P., et al., 2011. Cyanobacterial LPS potentiates cadmium toxicity in zebrafish (Danio rerio) embryos. Environ. Toxicol., 26(5):498-505. [doi:10.1002/tox.20578]

Osterauer, R., Fassbender, C., Braunbeck, T., et al., 2011. 
Genotoxicity of platinum in embryos of zebrafish (Danio rerio) and ramshorn snail (Marisa cornuarietis). Sci. Total Environ., 409(11):2114-2119. [doi:10.1016/j.scitotenv. 2011.01.060]

Sassi, A., Darias, M.J., Said, K., et al., 2013. Cadmium exposure affects the expression of genes involved in skeletogenesis and stress response in gilthead sea bream larvae. Fish Physiol. Biochem., 39(3):649-659. [doi:10. 1007/s10695-012-9727-9]

Shi, X., Du, Y., Lam, P.K., et al., 2008. Developmental toxicity and alteration of gene expression in zebrafish embryos exposed to PFOS. Toxicol. Appl. Pharmacol., 230(1):23-32. [doi:10.1016/j.taap.2008.01.043]

Singh, D., Keshker, G., Jangde, A.K., 2008. Study of water quality parameters and $\mathrm{Pb}$ and $\mathrm{Cd}$ concentration distribution in the Hasdeo River in Korba (India). J. Environ. Res. Dev., 3(1):185-190.

Souid, G., Souayed, N., Yaktiti, F., et al., 2013. Effect of acute cadmium exposure on metal accumulation and oxidative stress biomarkers of Sparus aurata. Ecotoxicol. Environ. Saf., 89:1-7. [doi:10.1016/j.ecoenv.2012.12.015]

Terry, P.A., Stone, W., 2002. Biosorption of cadmium and copper contaminated water by Scenedesmus abundans. Chemosphere, 47(3):249-255. [doi:10.1016/S0045-6535 (01)00303-4]

Tilton, F., Tanguay, R.L., 2008. Exposure to sodium metam during zebrafish somitogenesis results in early transcriptional indicators of the ensuing neuronal and muscular dysfunction. Toxicol. Sci., 106(1):103-112. [doi:10.1093/ toxsci/kfn145]

Timme-Laragy, A.R., Cockman, C.J., Matson, C.W., et al., 2007. Synergistic induction of AHR regulated genes in developmental toxicity from co-exposure to two model PAHs in zebrafish. Aquat. Toxicol., 85(4):241-250. [doi:10. 1016/j.aquatox.2007.09.005]

Udomchoke, V., Sunthornranun, P., Songsasen, A., et al., 2010. The ecological complexity of the Thai-Laos Mekong River: I. Geology, seasonal variation and human impact assessment on river quality. J. Environ. Sci. Health A: Tox. Hazard. Subst. Environ. Eng., 45(13):1661-1673. [doi:10.1080/10934529.2010.513207]
Vergauwen, L., Hagenaars, A., Blust, R., et al., 2013. Temperature dependence of long-term cadmium toxicity in the zebrafish is not explained by liver oxidative stress: evidence from transcript expression to physiology. Aquat. Toxicol., 126:52-62. [doi:10.1016/j.aquatox.2012.10.004]

Walker, J.M., 1994. The bicinchoninic acid (BCA) assay for protein quantitation. Methods Mol. Biol., 32:5-8. [doi:10. 1385/0-89603-268-X:5]

Wang, L., Gallagher, E.P., 2013. Role of Nrf2 antioxidant defense in mitigating cadmium-induced oxidative stress in the olfactory system of zebrafish. Toxicol. Appl. Pharmacol., 266(2):177-186. [doi:10.1016/j.taap.2012. 11.010]

Weil, M., Scholz, S., Zimmer, M., et al., 2009. Gene expression analysis in zebrafish embryos: a potential approach to predict effect concentrations in the fish early life stage test. Environ. Toxicol. Chem., 28(9):1970-1978. [doi:10. 1897/08-627.1]

Wiegand, C., Pflugmacher, S., Oberemm, A., et al., 1999. Uptake and effects of microcystin-LR on detoxication enzymes of early life stages of the zebra fish (Danio rerio). Environ. Toxicol., 14(1):89-95. [doi:10.1002/(SICI)15227278(199902)14:1<89::AID-TOX12>3.0.CO;2-7]

Wills, L.P., Zhu, S., Willett, K.L., et al., 2009. Effect of CYP1A inhibition on the biotransformation of benzo[a]pyrene in two populations of Fundulus heteroclitus with different exposure histories. Aquat. Toxicol., 92(3): 195-201. [doi:10.1016/j.aquatox.2009.01.009]

Yang, S., Xie, J., Li, Q., 2012. Oxidative response and antioxidative mechanism in germinating soybean seeds exposed to cadmium. Int. J. Environ. Res. Public Health, 9(12):2827-2838. [doi:10.3390/ijerph9082827]

Yu, K.N., Tung, M.M., Choi, V.W., et al., 2012. Alpha radiation exposure decreases apoptotic cells in zebrafish embryos subsequently exposed to the chemical stressor, Cd. Environ. Sci. Pollut. Res. Int., 19(9):3831-3839. [doi:10.1007/s11356-012-1032-8]

Zhang, Z., Huang, J., Yu, G., et al., 2004. Occurrence of PAHs, PCBs and organochlorine pesticides in the Tonghui River of Beijing, China. Environ. Pollut., 130(2):249-261. [doi:10.1016/j.envpol.2003.12.002]

\section{中文笨要：}

\section{本文题目：硫酸镉与 $\boldsymbol{\alpha}$-蒜黄酮对斑马鱼发育的个体毒性与联合毒性研究}

Individual and joint toxic effects of cadmium sulfate and $\alpha$-naphthoflavone on the development of zebrafish embryo

研究目的：研究硫酸镉与 $\alpha$-䒺黄酮对斑马鱼发育的个体毒性与联合毒性，并探讨其中的联合毒性机制。

创新要点: 首次对硫酸镉与 $\alpha$-薺黄酮的联合毒性进行了研究, 并探索了氧化应激、ATP 结合盒式 (ABC) 转运 蛋白及细胞色素 P450 蛋白（CYP）1A 在化合物联合毒性中的作用。

研究方法: 在不同时间点, 依据形态学指标检测硫酸镉与 $\alpha$-䒺黄酮单独使用与联合使用时对斑马鱼胚胎的致死 与致畸性毒性。取样品，采用试剂盒检测不同处理状态下斑马鱼胚胎中谷胱甘肽（GSH）、超氧化 物歧化酶（SOD）及丙二醛（MDA）三个氧化还原指标的改变, 聚合酶链式反应（PCR）检测样品 中多药耐药蛋白 $(\mathrm{mrp}) 1$ 及 $\mathrm{cypla}$ 基因表达水平的改变。

重要结论: 硫酸镉与 $\alpha$-慕黄酮的联用能够产生远大于个体且显著增强各自的毒性, 而这种增强作用机理在于氧 化应激压力的产生，以及两者合用下 $m r p 1$ 及 cypla 基因表达水平的改变。

关键词组：联合毒性；硫酸镉； $\alpha$-苶黄酮；斑马鱼胚胎；氧化应激压力 